\title{
Deuterium trapping and surface modification of polycrystalline tungsten exposed to a high-flux plasma at high fluences
}

\author{
M. Zibrov a,b,c,d,e, M. Balden ${ }^{\mathrm{a}}$, T.W. Morgan ${ }^{\mathrm{b}}$, M. Mayer $^{\mathrm{a}}$ \\ ${ }^{a}$ Max-Planck-Institut für Plasmaphysik, Boltzmannstraße 2, D-85748 Garching, Germany \\ ${ }^{b}$ DIFFER - Dutch Institute for Fundamental Energy Research, De Zaale 20, 5612 AJ Eindhoven, the Netherlands \\ ${ }^{c}$ Department of Applied Physics, Ghent University, Sint-Pietersnieuwstraat 41, B-9000 Ghent, Belgium \\ ${ }^{d}$ Physik-Department E28, Technische Universität München, James-Franck-Straße 1, D-85748 Garching, Germany \\ ${ }^{e}$ National Research Nuclear University MEPhI (Moscow Engineering Physics Institute), Kashirskoe shosse 31, 115409 Moscow, Russia
}

E-mail: Mikhail.Zibrov@ipp.mpg.de

\begin{abstract}
Deuterium (D) retention and surface modifications of hot-rolled polycrystalline tungsten (W) exposed to a low-energy ( 40 eV/D), high-flux $\left(2-5 \times 10^{23} \mathrm{D} / \mathrm{m}^{2} \mathrm{~s}\right) \mathrm{D}$ plasma at temperatures of $\sim 380 \mathrm{~K}$ and $\sim 1140 \mathrm{~K}$ to fluences up to $1.2 \times 10^{28} \mathrm{D} / \mathrm{m}^{2}$ have been examined by using nuclear reaction analysis, thermal desorption spectroscopy, and scanning electron microscopy. The samples exposed at $\sim 380 \mathrm{~K}$ exhibited various types of surface modifications: dome-shaped blister-like structures, stepped flat-topped protrusions, and various types of nanostructures. It was observed that a large fraction of the surface was covered with blisters and protrusions, but their average size and the number density showed almost no fluence dependence. The $\mathrm{D}$ depth distributions and total $\mathrm{D}$ inventories also barely changed with increasing fluence at $\sim 380 \mathrm{~K}$. A substantial amount of D was retained in the subsurface region, which thickness correlated with the depth where the cavities of blisters and protrusions were located. It is therefore suggested that defects appearing during creation of blisters and protrusions govern the D trapping in the investigated fluence range. In addition, a large number of small cracks was observed on the exposed surfaces, which can serve as fast D release channels towards the surface, resulting in a reduction of the effective $\mathrm{D}$ influx into the $\mathrm{W}$ bulk. On the samples exposed at $\sim 1140 \mathrm{~K}$ no blisters and protrusions were found. However, wave-like and faceted terrace-like structures were formed instead. The concentrations of trapped D were very low $\left(<10^{-5}\right.$ at. fr. $)$ after the exposure at $\sim 1140 \mathrm{~K}$.
\end{abstract}

Keywords: Tungsten, Deuterium retention, Surface modifications, Blistering, High fluences 


\section{Introduction}

Tungsten (W) will be used as a plasma-facing material in the divertor region in ITER, and its use in future fusion devices is also foreseen [1,2]. Among many concerns that need to be examined for the assessment of the possibility of $\mathrm{W}$ use in future fusion reactors, the issues of hydrogen $(\mathrm{H})$ isotope retention (especially of radioactive tritium) in plasma-facing components, their re-emission into the plasma (recycling), and permeation into the cooling system are one of the most important [2]. Although many properties of the H-W system, such as $\mathrm{H}$ solubility in $\mathrm{W}, \mathrm{H}$ interaction with lattice defects in $\mathrm{W}$, as well as surface modifications and integral characteristics of $\mathrm{H}$ retention in $\mathrm{W}$ under various exposure conditions have been studied quite extensively, the results reported by different researchers show a very large scatter and are sometimes even contradictory [3,4]. Such differences can be attributed to many factors, including differences in experimental arrangements (e.g. use of mass-separated ion beams or plasma for irradiation, presence of impurities in the plasma), differences in used $\mathrm{W}$ grades (microstructure, impurity content, surface finish, etc.) [5-8], as well as differences in their heat treatment prior to irradiation $[6,9]$, different surface conditions of samples during irradiation $[10,11]$, differences in storage conditions after irradiation (in vacuum or in air) [12], the lag time between irradiation and post-mortem analyses (e.g. Thermal Desorption Spectroscopy (TDS), Nuclear Reaction Analysis (NRA), Secondary Ion Mass Spectrometry (SIMS), etc.) [11, 12], and, possibly, some other factors. In addition, the $\mathrm{H}$ retention in $\mathrm{W}$ also depends on the incident ion flux, not only on the total incident fluence. This effect was observed in experiments with mass-separated ion beams [13], as well as with plasma exposure $[7,14,15]$. According to the present understanding, the flux effect on $\mathrm{H}$ retention in metals is a consequence of the interplay between at least the following factors: 1 . the solute $\mathrm{H}$ concentration caused by the impinging ion flux, which determines the $\mathrm{H}$ diffusive flux into the bulk and the equilibrium occupancy of trapping sites with $\mathrm{H} ; 2$. the flux dependence of the rate of creation of plasma-induced damage in the material (e.g. blister-like structures, $\mathrm{H}$ bubbles); 3. the duration of irradiation needed to accumulate a certain incident fluence, which affects the $\mathrm{H}$ diffusion length in the material during the exposure. One must also bear in mind that at sufficiently high incident fluxes the plasma-material system is strongly coupled, which means that the mean free-path of neutral $\mathrm{H}$ atoms or molecules recycled from the material is smaller compared to the characteristic size of the plasma beam, which results in such phenomena like plasma detachment. Consequently, the results of experiments at low incident ion fluxes cannot be always correctly extrapolated to high-flux conditions. Thus, in order to 
make reliable predictions of $\mathrm{H}$ isotope retention in plasma-facing components, the laboratory experiments must be carried out in reactor-relevant conditions.

Since in ITER particle fluxes of the order of $10^{24} \mathrm{ions} / \mathrm{m}^{2} \mathrm{~s}$ on $\mathrm{W}$ plasma-facing components close to the divertor strike-points are expected and the pulse duration will be near $400 \mathrm{~s}$, fluences above $10^{26}$ ions $/ \mathrm{m}^{2}$ will be reached after one pulse. As a result, fluences in excess of $10^{30}$ ions $/ \mathrm{m}^{2}$ will be reached by the end of ITER operation. However, in experiments performed so far fluences did not exceed $10^{27} \mathrm{ions} / \mathrm{m}^{2}$ [3, 14-19]. Only in recent experiments at PISCES-B W targets were exposed to a deuterium (D) plasma to fluences up to $2 \times 10^{28} \mathrm{D} / \mathrm{m}^{2}$. However, the exposures were carried out only at one temperature of $640 \mathrm{~K}$ and the surface modifications of the exposed targets were not studied in detail [20]. Consequently, a more detailed study of $\mathrm{D}$ retention and surface modifications of $\mathrm{W}$ exposed to a high-flux D plasma at high fluences and various surface temperatures is necessary.

In the present contribution these questions were examined for two limiting cases: exposure at low target temperatures $(\sim 380 \mathrm{~K})$, at which many laboratory experiments at low incident fluxes have been carried out, and at high temperatures $(\sim 1140 \mathrm{~K})$, which are expected for ITER divertor tiles near the strike point [2]

\section{Experimental details}

Samples made of hot-rolled polycrystalline $\mathrm{W}$ discs (20 mm diameter, $1 \mathrm{~mm}$ thickness) with a purity of 99.97 wt.\% supplied by PLANSEE (Austria) were used. The samples were first grinded with a SiC sand paper and then polished to a mirror finish with diamond and $\mathrm{SiO}_{2}-$ containing suspensions. Then they were ultrasonically cleaned in acetone and annealed at $1173 \mathrm{~K}$ at a pressure below $1 \times 10^{-4} \mathrm{~Pa}$ for 2 hours to release residual hydrogen and relieve stresses produced by manufacturing and polishing. No significant structural modifications in the samples are expected to occur at this temperature, therefore the samples are considered to be in a stress-relieved state [9]. The $\mathrm{W}$ grade used in the present study and that studied in [5$7,9,14,21]$ were produced by the same method by the same manufacturer and have the same nominal purity; the only difference was that they originated from different manufacturing batches and had different final thicknesses. In addition, the two grades had similar microstructures - flattened grains elongated parallel to the surface with a length up to a few $\mu \mathrm{m}$ and a thickness up to $1 \mu \mathrm{m}$ (perpendicular to the surface). 
The samples were exposed to a pure D plasma in the linear plasma generator Pilot-PSI (DIFFER, the Netherlands) [22, 23]. The base pressure in the vacuum chamber obtained by two mechanical booster pumps in series with a rotary vane pump was $\sim 10^{-1} \mathrm{~Pa}$ which increased to $\sim 1 \mathrm{~Pa}$ during the plasma operation. The $\mathrm{D}$ plasma was generated by a DC cascaded arc source and transported to the target by applying a constant axial magnetic field of $0.2 \mathrm{~T}$. The plasma beam consisted of predominantly $\mathrm{D}^{+}$ions due to its low temperature and high density [24]. The investigation of the plasma column close to the surface of an exposed target with optical emission spectroscopy (wavelength range $299-579 \mathrm{~nm}$, integration time $1 \mathrm{~ms}$ ) showed the presence of Balmer series lines only, indicating that the impurity content in the plasma was below the sensitivity limit of the spectroscopic method. Electron density $n_{e}$ and temperature $T_{e}$ profiles of the plasma beam were measured by Thomson scattering at a distance of about $2 \mathrm{~cm}$ from the target. The plasma parameters of the beam had approximately Gaussian radial distributions with a maximum electron density and temperature not exceeding $8 \times 10^{13} \mathrm{~cm}^{-3}$ and $1 \mathrm{eV}$, respectively. The ion flux on the targets $\Gamma$ was derived from the Bohm criterion [25]:

$$
\Gamma=\frac{1}{2} n_{e} \sqrt{\frac{k\left(T_{e}+\gamma T_{i}\right)}{M}},
$$

where $T_{i}$ - ion temperature, which was assumed to be equal to the electron temperature, $M-$ mass of a $\mathrm{D}$ ion, the $\gamma$ was assumed to be $5 / 3$ (an adiabatic flow with isotropic pressure), and $k$ - Boltzmann constant. The calculated radial flux distribution had a Gaussian profile with a full width at half maximum (FWHM) in the range of 15-20 mm and varied in the range of $2-5 \times 10^{23} \mathrm{D} / \mathrm{m}^{2} \mathrm{~s}$ in the beam centre. The flux profile was integrated over the exposed surface of the sample to yield the average incident ion flux. The difference between the flux (and, correspondingly, the fluence) in the beam centre and the averaged one over the entire exposed area of the specimen was within $30 \%$. Later in the text, the values of the incident fluence and surface temperature in the sample centre will be used.

The targets were clamped to a water-cooled copper holder with a Grafoil® flexible graphite interlayer by using a clamping ring made of TZM alloy. The centre of the plasma beam matched with the centre of the specimens. A bias voltage of $-40 \mathrm{~V}$ was applied to the target holder during exposures. Although the plasma potential was not measured in the present experiments, due to the very low electron temperature of the plasma $(\leq 1 \mathrm{eV})$ the plasma potential should be only a few eV [25]. Consequently, the mean incident energy of the D ions was near $40 \mathrm{eV}$. The lateral distribution of the surface temperature of the targets 
during plasma exposures was measured with a fast infrared (IR) camera (FLIR SC7500-MB) by using a value of the $\mathrm{W}$ emissivity of 0.1 . In the case of exposure at temperatures above $800 \mathrm{~K}$, the surface temperature in the sample centre was also monitored by an IR spectral pyrometer (FAR associates FMPI) where the diameter of the collecting area was $\sim 1 \mathrm{~mm}$. Adjustment of the surface temperatures of the samples was obtained by varying the physical contact of the sample with the holder and by varying the incident ion flux. Steady-state plasma exposures of the samples were carried out with exposure times ranging from 15 min to $8 \mathrm{~h}$, resulting in incident fluences in the range of $5 \times 10^{26} \mathrm{D} / \mathrm{m}^{2}-1.2 \times 10^{28} \mathrm{D} / \mathrm{m}^{2}$. Compared to most of the previous studies performed at Pilot-PSI (e.g. [8, 14, 15, 17, 18, 26-30]) where the plasma exposures were carried out in a pulsed mode (with a pulse length $<160 \mathrm{~s}$ ), in the present experiments steady-state plasma exposures (but with lower incident fluxes) were carried out.

Two series of experiments were performed. In the first series the samples were exposed at a surface temperature in the sample centre of $\sim 380 \mathrm{~K}$. The difference in the temperature between the centre of the sample and the edges was typically within $30 \mathrm{~K}$. In the second series of experiments, the samples were exposed at a surface temperature in the sample centre (as measured by an IR spectral pyrometer) of $\sim 1140 \mathrm{~K}$. The difference in the temperature between the centre of the sample and the edges was within $250 \mathrm{~K}$. The targets reached the equilibrium temperature within $10 \mathrm{~s}$ after switching on the plasma beam and bias. The cooling of the targets to room temperature after switching off the beam and bias also occurred within that time. The variation of the surface temperature in the sample centre between different exposures was within $10 \mathrm{~K}$, and the difference between the surface temperatures at the beginning and at the end of exposures was also within $10 \mathrm{~K}$.

D depth distributions in the samples up to a depth of $7 \mu \mathrm{m}$ were measured using nuclear reaction analysis (NRA) at the $3 \mathrm{MV}$ tandem accelerator (IPP, Garching) about three months after the plasma exposure. The $\mathrm{D}\left({ }^{3} \mathrm{He}, \mathrm{p}\right) \alpha$ reaction was used, and the energy of the ${ }^{3} \mathrm{He}$ ion beam was varied in the range of $0.5 \mathrm{MeV}-4.5 \mathrm{MeV}$ to obtain data from different sample depths [31]. Both protons and $\alpha$ energy spectra were transformed into D concentration profiles using the SIMNRA [32] and NRADC [33] programmes.

The total amounts of retained $\mathrm{D}$ in the samples were determined by using thermal desorption spectroscopy (TDS) in the TESS installation [34] (IPP, Garching). The samples were placed in a quartz tube and heated by radiation from an external furnace up to a temperature of $1270 \mathrm{~K}$ at a background pressure below $10^{-6} \mathrm{~Pa}$. The furnace was linearly 
heated with a rate of $0.25 \mathrm{~K} / \mathrm{s}$. The real sample temperature versus the measured oven temperature was calibrated in an independent experiment by a thermocouple spot-welded to the sample. At the beginning of the temperature ramp, the heating rate was nonlinear up to about $800 \mathrm{~K}$. The release of 10 masses was monitored by a quadrupole mass spectrometer (QMS). In order to determine the total amount of retained D, the QMS signal for mass $4\left(\mathrm{D}_{2}\right)$ was calibrated using a NIST-traceable calibrated leak. The relative QMS sensitivities for masses 3 (HD) and 4 were determined by using the procedures described in [35]. As a rough estimation, the relative sensitivities of $\mathrm{D}_{2} \mathrm{O}$ to $\mathrm{D}_{2}$ and of HDO to HD were assumed to be the same as that of $\mathrm{H}_{2} \mathrm{O}$ to $\mathrm{H}_{2}$, which was taken from [36]. The amount of D released in the form of $\mathrm{HDO}$ and $\mathrm{D}_{2} \mathrm{O}$ molecules was then considered as an upper limit of the uncertainty for the total retention measurement.

The surface morphology of the samples after the plasma exposure was investigated in a scanning electron microscope (SEM) FEI HELIOS NanoLab 600 (IPP, Garching), which is equipped with a $\mathrm{Ga}^{+}$focused ion beam (FIB) allowing in situ cross-sectioning and imaging of the specimens. The cross-sections were imaged at $38^{\circ}$ tilt, causing a difference between the horizontal and vertical scales - the length of the vertical scale bars in the images are 0.79 of the horizontal scale bars. In order to reduce artefacts of the cutting process, the area of interest was coated in situ with a Pt-C film prior to the cutting. In addition, the presence of impurities on the exposed surfaces was examined by energy-dispersive X-ray spectroscopy (EDX).

\section{Experimental results and discussion}

\subsection{Surface modifications}

\subsubsection{Low temperatures}

Various types of surface modifications were formed on the surfaces of the samples exposed at $\sim 380 \mathrm{~K}$ (Fig. 1). Firstly, dome-shaped blister-like structures with nearly elliptic outlines and diameters up to $10 \mu \mathrm{m}$ were found (e.g. Fig. 1 b). Later in the text, these structures will be referred to as "blisters". These structures were irregularly distributed over the surface and often appeared in groups. Quite frequently they also extended over more than one grain. Stepped flat-topped and irregularly-shaped structures with sharp edges and dimensions ranging from $100 \mathrm{~nm}$ to several $\mu \mathrm{m}$ were also found (e.g. Fig. 1 b, c). These structures will be referred to as "protrusions". Compared to blisters, such structures usually appeared within a single grain, whilst their distribution over the surface was also 
inhomogeneous. Some of the protrusions were found on top of blisters and larger protrusions (Fig. $1 \mathbf{b}, \mathbf{e}, \mathbf{h})$. It can be also noted that the areal density of protrusions was higher compared to the density of blisters, and, in addition, already at the lowest fluence used $\left(5 \times 10^{26} \mathrm{D} / \mathrm{m}^{2}\right)$ a noticeable fraction of the exposed surface was covered with protrusions (Fig. 1 b). Despite more than one order of magnitude variation of the incident fluence, the appearance of blisters and protrusions, namely their number density and average size, barely changed with increasing fluence. Furthermore, grains without any blister and protrusion were also present, which is consistent with previously reported results [19, 29]. It should be noted, however, that the method of surface preparation could potentially influence the appearance of the observed surface modifications [8].

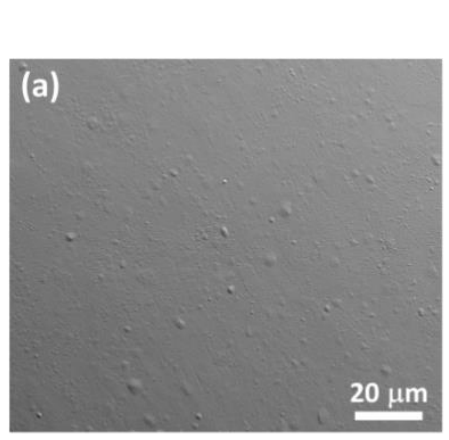

$5 \times 10^{26} \mathrm{D} / \mathrm{m}^{2}$

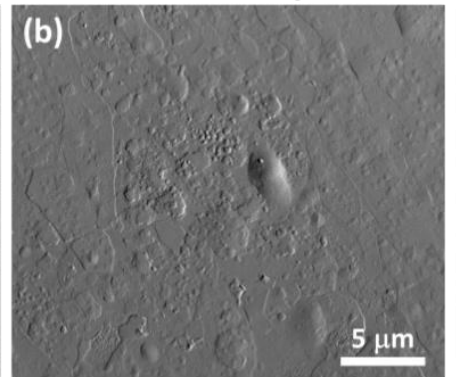

$1.4 \times 10^{27} \mathrm{D} / \mathrm{m}^{2}$
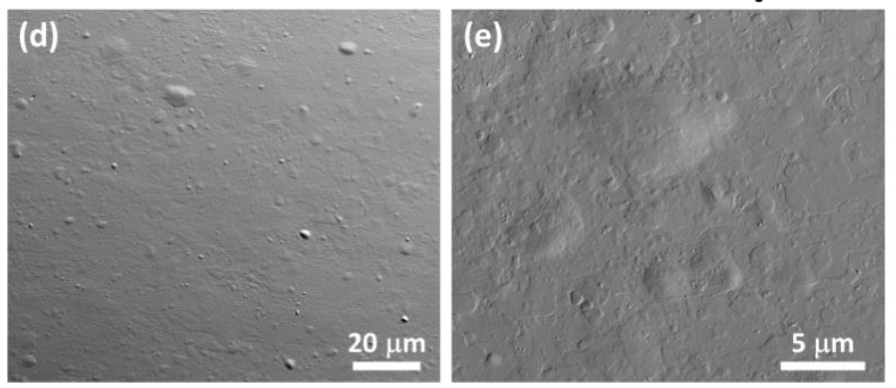

$1.2 \times 10^{28} \mathrm{D} / \mathrm{m}^{2}$
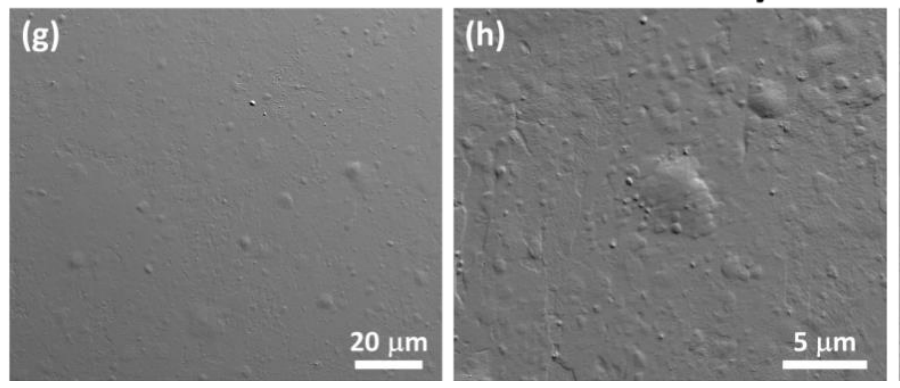
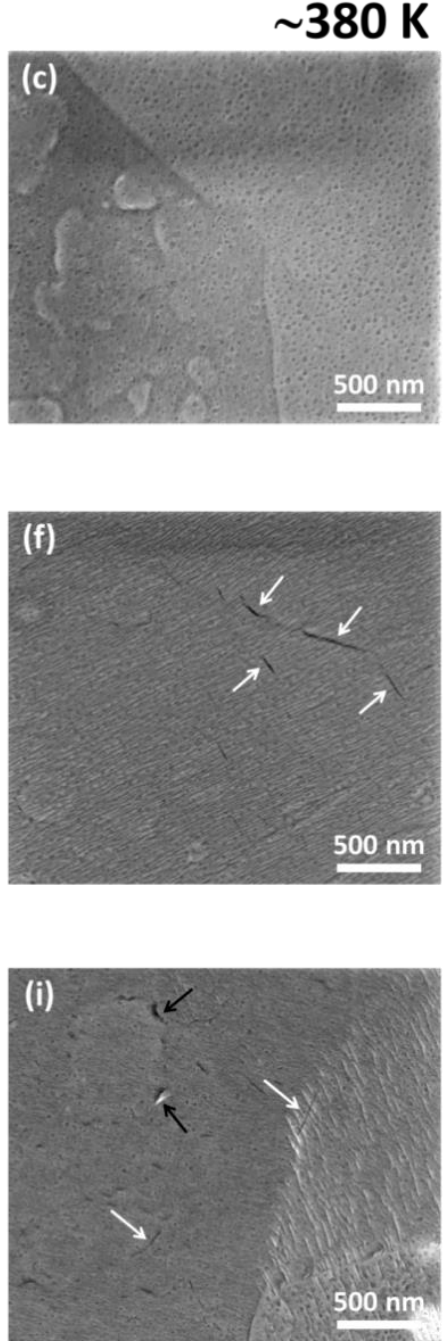

Fig. 1. A series of SEM images with different magnifications of polycrystalline $\mathrm{W}$ exposed to a $\mathrm{D}$ plasma at a temperature of $\sim 380 \mathrm{~K}$ to different fluences: (a)-(c) $5 \times 10^{26} \mathrm{D} / \mathrm{m}^{2}$; (d)-(f) $1.4 \times 10^{27} \mathrm{D} / \mathrm{m}^{2}$; (g)-(i) $1.2 \times 10^{28} \mathrm{D} / \mathrm{m}^{2}$. Cracks near edges of protrusions are indicated by the black arrows, whereas cracks on the flat regions of the surface are indicated with white arrows. The images were taken in the centres of the samples. The exposure temperature and fluences are valid for the sample centre. 
In addition, all the samples exposed at $\sim 380 \mathrm{~K}$ exhibited the presence of structures with lateral dimensions of several tens of nm (Fig. 1 c, f, i). They mostly appeared as stripe-like and sponge-like structures. Such nanostructuring was previously observed both after high-flux $\left(\sim 10^{24} \mathrm{D} / \mathrm{m}^{2} \mathrm{~s}\right)[14,26,28]$ and low-flux $\left(10^{20} \mathrm{D} / \mathrm{m}^{2} \mathrm{~s}\right)[7,14]$ plasma exposures and was attributed to sputtering of the surface by impurities in the plasma beam. The type of nanostructure changed at some of the grain boundaries (Fig. 1 i), suggesting that the type of the structure depended on the grain orientation, as was shown by Xu et al. [26] and Jia et al. [28].

SEM investigations also revealed the presence of a large number of small cracks with lengths up to several hundred $\mathrm{nm}$ on the exposed surfaces. The lowest fluence at which the cracks could be unambiguously detected was $1.4 \times 10^{27} \mathrm{D} / \mathrm{m}^{2}$, although their presence on the samples exposed to lower fluences cannot be excluded. Such cracks were observed both on the top and near edges of blisters (not shown here), as well as on the top of and near edges of protrusions (indicated by the black arrows in Fig. 1 i). Moreover, the cracks were also observed on relatively flat regions of the surface, where no apparent blisters or protrusions could be detected (indicated by the white arrows in Fig. $1 \mathbf{f}, \mathbf{i}$ ). Due to the fact that the cracks were typically quite small and could be detected only at high magnifications, it is not possible to state with statistical confidence which fraction of blisters and protrusions had cracks and the evolution of the number of cracks with increasing fluence. Fig. 2 shows an example of a protrusion with cracks visible on its top and near its edges. Images shown in Fig. 2 a and b represent the same region of the sample, but were taken with different SEM modes in order to highlight different features. In order to increase the topography contrast, Fig. 2 a was taken in a custom mode of a segmented concentric backscatter electron detector (CBS) of SEM, where the difference of the signals from two segments of the detector was used. On the other hand, Fig. 2 b was taken in a Z-contrast mode of the CBS detector (i.e. the sum of the signals from all segments of the detector) in which the cracks were better visible. Cross-sectioning of this protrusion (Fig. 2 c) revealed that its cavity was formed by a crack following a grain boundary (inter-granular) running parallel to the surface and located at a depth of $\sim 500 \mathrm{~nm}$. Furthermore, many additional cracks can be also seen in the cross-sectional image. One of the cracks visible in Fig. $2 \mathbf{c}$ was formed along the grain boundary and intersected the surface (see right arrow). A number of small cracks intersecting the surface (marked with a rectangle) were also formed within a single grain (intra-granular). In addition, intra-granular cracks located at depths typically below $100 \mathrm{~nm}$, which did not intersect the surface, were present as well (marked with ellipses). The latter cracks presumably correspond to very small 
protrusions $[14,21]$, which cannot be well seen in SEM due to the developed roughness of the surface (by nanostructuring).

The fact that cracks were observed on flat regions of the surface, as well as that the cracks observed on top of the protrusion did not reach its cavity indicate that the appearance of cracks cannot be only explained by rupture of a blister/protrusion cap due to high internal $\mathrm{D}_{2}$ gas pressure. It can be hypothesized that such cracks can have the same origin as the intragranular cracks associated with protrusions, since their cavities were sometimes found to be inclined to the surface $[14,30,37]$.

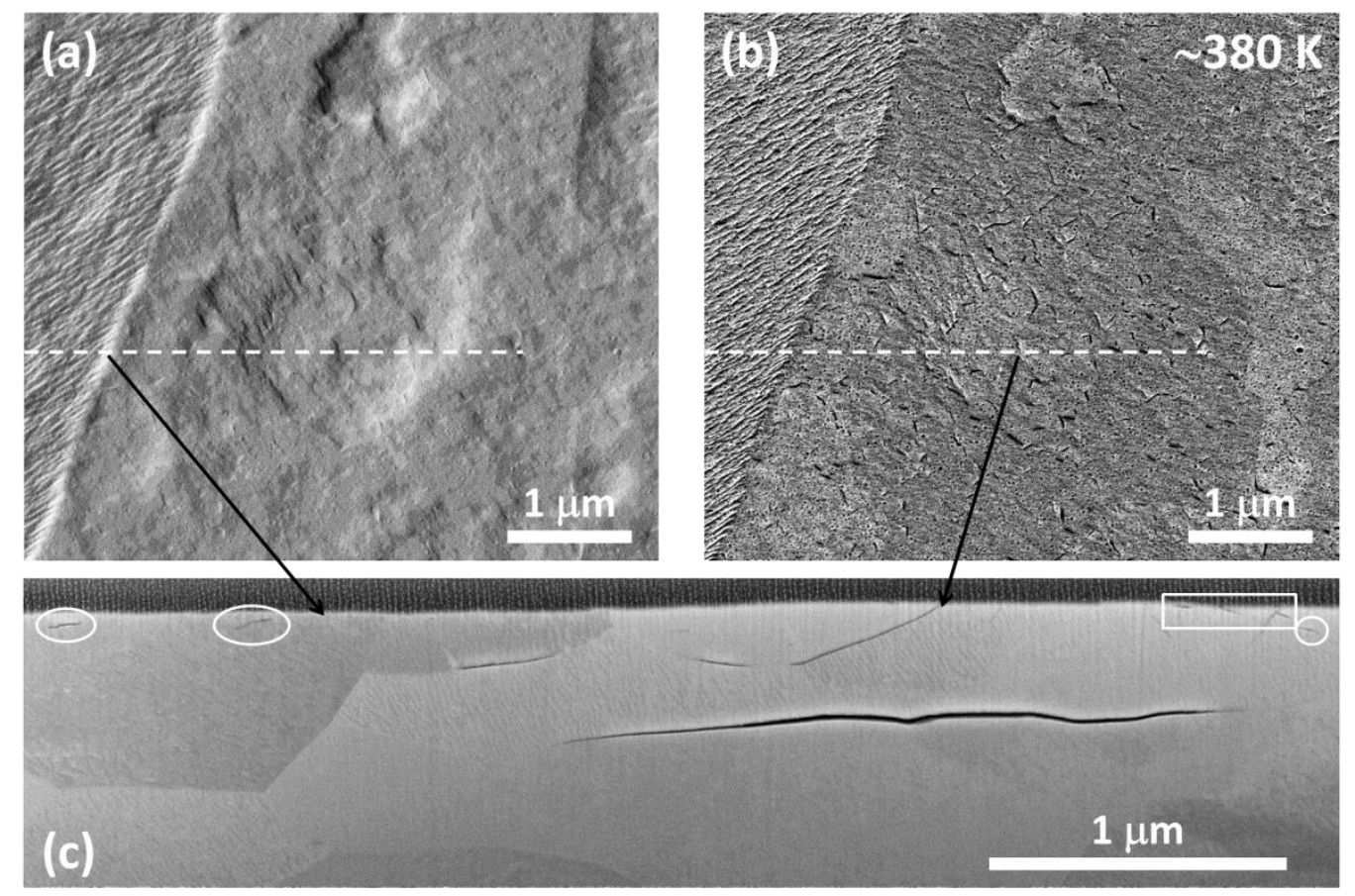

Fig. 2. Polycrystalline $\mathrm{W}$ exposed to a $\mathrm{D}$ plasma at a temperature of $\sim 380 \mathrm{~K}$ to a fluence of $1.2 \times 10^{28} \mathrm{D} / \mathrm{m}^{2}$ : SEM image of a protrusion with a number of cracks visible on its top and near its edges taken (a) in the custom mode of the CBS detector to highlight the topography, (b) in the Zcontrast mode of the CBS detector to highlight the appearance of cracks; (c) SEM image of a crosssection at the position indicated by the dashed line in (a) and (b). The surface in (c) was protected by

an amorphous Pt-C layer before cutting. The intra-granular cracks that intersect the surface are indicated with a rectangle, whereas the intra-granular cracks that do not intersect the surface are indicated with ellipses. The black arrows indicate the same features in (a), (b), and (c). The images were taken in the centre of the sample. The exposure temperature and fluence are valid for the sample centre.

In general, as was already discussed in literature $[6,7,14-16,21,30]$, the features of blisters/protrusions and their appearance mainly depend on the $\mathrm{W}$ grade used, on incident ion energy, ion flux, fluence, and the surface temperature. Under the present high-flux plasma exposure conditions both dome-shaped blisters and stepped flat-topped protrusions were formed on hot-rolled W. The protrusions were shown to be formed both by inter- and intra- 
granular cracking. Exposure of the same type of material to a low-flux $\left(10^{20} \mathrm{D} / \mathrm{m}^{2} \mathrm{~s}\right) \mathrm{D}$ plasma at a similar temperature $(370 \mathrm{~K})$ resulted in formation of only blisters, which cavities were shown to be formed by inter-granular cracking [6]. This indicates that the morphological modifications of the surface strongly depend on the incident ion flux. However, it was recently demonstrated that even under low-flux exposure conditions both blisters and protrusions (formed by intra-granular cracking) can be formed, but then the exposure temperature has to be as low as $230 \mathrm{~K}$ [21]. Several experimental evidences gave rise to the hypothesis that a high local solute $\mathrm{D}$ concentration near the nucleation centres acts as a driving force for the creation of blisters and protrusions $[1,21]$. The solute D concentration can be increased either by increasing the incident ion flux or by decreasing the D diffusivity, e.g. by reducing the exposure temperature. Thus, under a low-flux plasma exposure at low temperatures similarly high concentrations of solute D as under a high-flux exposure at elevated temperatures can be reached. Consequently, it can be suggested that for initiation of an intra-granular crack the local solute D concentration during the plasma exposure should exceed some threshold value. The mechanisms of further development of blisters and protrusions, explaining also their differences, are not yet clear and still under discussion [1, 4].

\subsubsection{High temperatures}

All the samples exposed at $~ 1140 \mathrm{~K}$ exhibited neither blistering nor nanostructuring of the surface. However, a different type of surface modification was detected. As an example, Fig. 3 shows an SEM image of the sample exposed to the fluence of $5 \times 10^{27} \mathrm{D} / \mathrm{m}^{2}$. As can be seen, the types of the surface modifications varied among different grains: some of the surface structures resembled wave-like structures (ripples), whereas other structures appeared more like faceted terraces. On some of the grains no modifications were detected. All these structures had characteristic dimensions of several hundreds of nanometres, i.e. an order of magnitude larger compared to the nanostructures on the surface observed after the exposure at $\sim 380 \mathrm{~K}$ (compare Fig. 3 and Fig. 1 c, f, i). On some of the exposed samples EDX analysis detected that a part of the wave- and terrace-like structures had a higher oxygen content compared to that on the unmodified grains. This can be also noted in SEM images recorded with secondary electrons, where these structures appeared much brighter compared to the surroundings (Fig. 3). A closer look on the bright regions revealed that most of the tops of wave-like structures were covered with a dielectric film (oxide); these dielectric films also partially exfoliated in some regions. The reason for the formation of these oxide layers is not 
clear, as during the high-flux bombardment with $\mathrm{H}$ isotopes oxide layers are expected to be removed. One possible explanation is that during the cooling-down of the samples after the plasma was switched off the samples could have been attacked by oxygen from the residual gas.

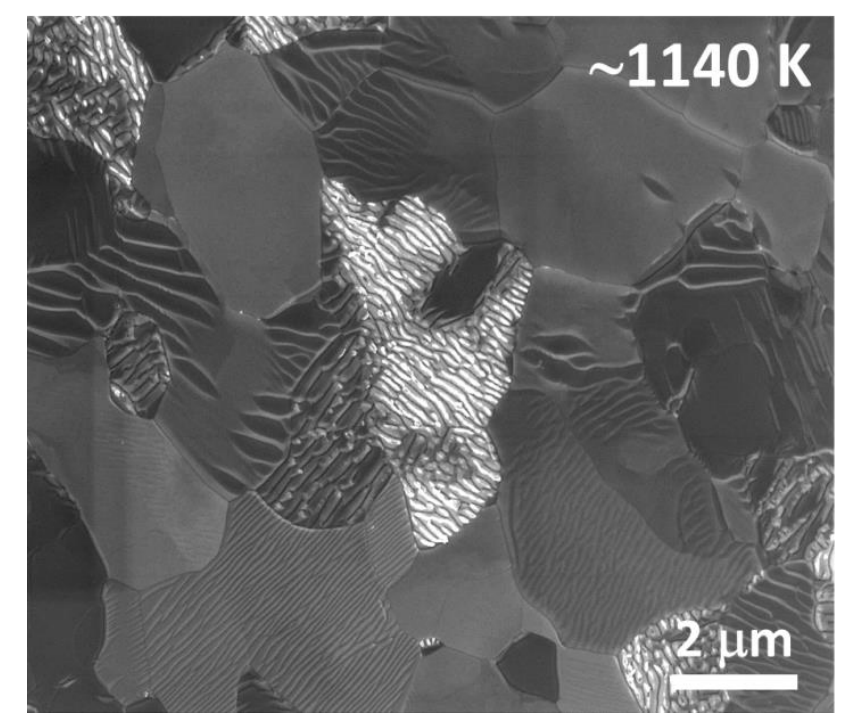

Fig. 3. SEM image of polycrystalline $\mathrm{W}$ exposed to a $\mathrm{D}$ plasma at a temperature of $\sim 1140 \mathrm{~K}$ to a fluence of $5 \times 10^{27} \mathrm{D} / \mathrm{m}^{2}$. The image was taken in the centre of the sample. The exposure temperature and fluence are valid for the sample centre.

\subsection{Deuterium retention}

\subsubsection{Low temperatures}

Fig. 4 shows the measured D depth distributions in the samples exposed at the temperature of $\sim 380 \mathrm{~K}$ to various fluences. The measurements were carried out in the sample centre. A lateral scan with $4.5 \mathrm{MeV}^{3} \mathrm{He}$ ions revealed that the variation of the $\mathrm{D}$ content across the plasma-exposed area was within $30 \%$ for all the specimens. As can be seen from Fig. 4, the evolution of the depth distributions with fluence was relatively small. In the first $25 \mathrm{~nm}$ near the surface the D concentration slightly increased with increasing fluence reaching a saturation value around 3 at.\%. At larger depths no clear tendencies with increasing fluence are visible. A substantial amount (above $80 \%$ ) of detected D was retained within the first $1.5 \mu \mathrm{m}$ near the surface for all the investigated samples. Comparison with the D depth distributions for the same type of material (hot-rolled W) but after the exposure to a low-flux $\left(10^{20} \mathrm{D} / \mathrm{m}^{2} \mathrm{~s}\right) \mathrm{D}$ plasma [6] leads to a striking observation: the depth distributions measured in the present work after the high-flux plasma exposure at $\sim 380 \mathrm{~K}$ strongly differed from those 
after the low-flux plasma exposure at a similar temperature $(370 \mathrm{~K})$; at the same time, they were quite similar to those after the low-flux exposure at $300 \mathrm{~K}$. A correlation between the D depth distributions and the occurrence of cavities of blisters and protrusions can be observed: The thickness of the subsurface region with a high $\mathrm{D}$ concentration $(\leq 1.5 \mu \mathrm{m})$ coincides with the depth up to which the cavities of blisters and protrusions were located (see Fig. 2). A similar correlation was also observed in low-flux experiments by Manhard [6]: At $300 \mathrm{~K}$ the blister cavities were located at depths below $1 \mu \mathrm{m}$, whereas at $370 \mathrm{~K}$ they were located at depths below $4 \mu \mathrm{m}$ (see Fig. 4). Thus, it can be suggested that creation of blisters and protrusions introduces a large number of defects in the subsurface region, which can act as trapping sites for D (e.g. cavities of blisters and protrusions, as well as additional defects generated during creation of blisters and protrusions). Consequently, the only small variations of the $\mathrm{D}$ depth distributions with fluence in the present study can be then attributed to the only small variations in number density and size of blisters and protrusions with fluence (see Sect. 3.1.1.). The difference between the present $\mathrm{D}$ depth distributions and those after the low-flux exposure at $370 \mathrm{~K}$ can be explained in terms of differences in depths where the cavities of blisters and protrusions were located.

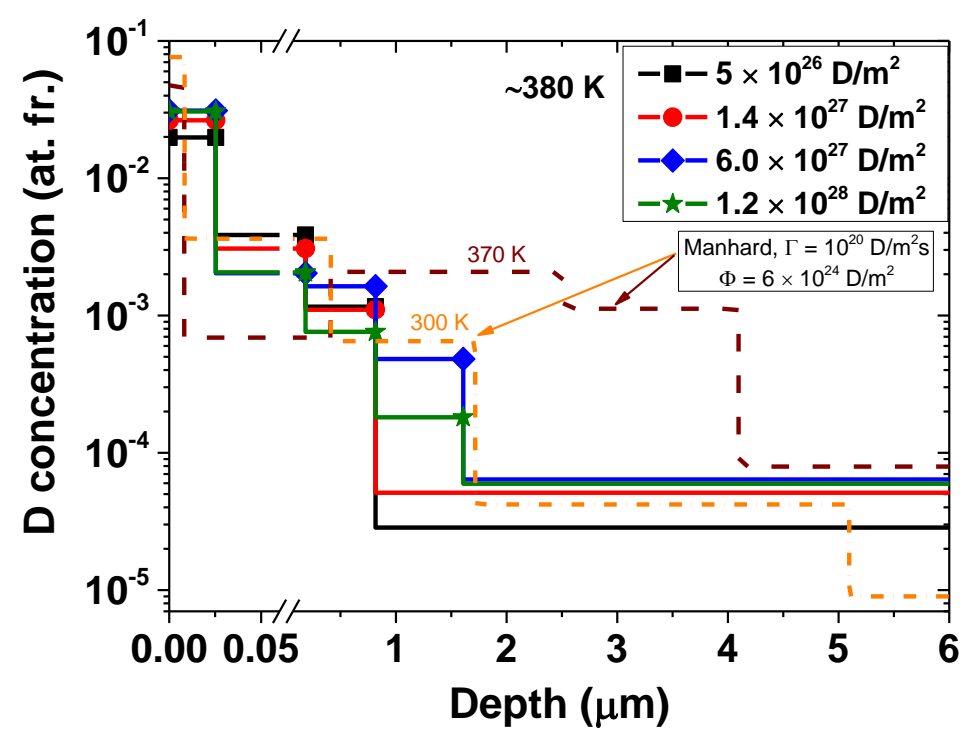

Fig. 4. D concentration profiles in polycrystalline $\mathrm{W}$ exposed to a $\mathrm{D}$ plasma at a temperature of $\sim 380 \mathrm{~K}$ to various fluences. The measurements were carried out in the sample centre. The exposure temperature and fluences are valid for the sample centre. For the comparison, the measurements performed by Manhard [6] for the same type of material (hot-rolled W), exposed to a low-flux D plasma $\left(10^{20} \mathrm{D} / \mathrm{m}^{2} \mathrm{~s}\right)$ with a mean ion energy of $38 \mathrm{eV} / \mathrm{D}$ to the fluence of $6 \times 10^{24} \mathrm{D} / \mathrm{m}^{2}$ at the temperatures of $300 \mathrm{~K}$ and $370 \mathrm{~K}$ are shown. 
Fig. 5 shows the fluence dependence of D retention for the samples exposed at $\sim 380 \mathrm{~K}$ measured by TDS and NRA. Please note that in this figure the values of D retention determined by NRA correspond to the local incident fluence in the sample centres, whereas the values of D retention determined by TDS correspond to the incident fluence averaged over the entire plasma-exposed area of the specimens. Both from the NRA and TDS data it can be concluded that the variation of the D uptake in the samples with incident fluence $\Phi$ was certainly slower than $\Phi^{1 / 2}$, i.e. far away from the ideal case of diffusion-limited trapping in time-independent traps with a homogeneous depth distribution. In addition, the D inventory itself was quite moderate - below $2 \times 10^{20} \mathrm{D} / \mathrm{m}^{2}$. It can be also noted that NRA gave 2-4 times higher retention compared to TDS (if only $\mathrm{D}$ release as $\mathrm{D}_{2}$ and $\mathrm{HD}$ molecules was considered). If the estimated contribution of heavy water (mainly HDO) was also taken into account, then the difference became smaller. The ratio of $\mathrm{D}$ released as $\mathrm{HDO}$ and $\mathrm{D}_{2} \mathrm{O}$ to the $\mathrm{D}$ released as $\mathrm{D}_{2}$ and $\mathrm{HD}$ was in the range of 0.6-1.4. It should be stressed again that the fraction of D released as heavy water was only very roughly estimated - just to indicate the significance of heavy water contribution in the present experiments; an accurate calibration of $\mathrm{HDO}$ and $\mathrm{D}_{2} \mathrm{O}$ signals was not possible. Another important fact that needs to be mentioned is that the TDS analysis was performed 6 months after NRA analysis for most of the specimens. Due to technical reasons, the measurements of the samples exposed to fluences of $1.4 \times 10^{27} \mathrm{D} / \mathrm{m}^{2}$ and $1.2 \times 10^{28} \mathrm{D} / \mathrm{m}^{2}$ were done 9 months after NRA analysis. The effect of D loss during the storage time - even on the timescale of months - was reported in literature $[11,12]$ and can also partially explain the discrepancy between NRA and TDS results, as well as that the samples exposed to fluences of $1.4 \times 10^{27} \mathrm{D} / \mathrm{m}^{2}$ and $1.2 \times 10^{28} \mathrm{D} / \mathrm{m}^{2}$ showed smaller $\mathrm{D}$ inventory (determined by TDS) compared to the rest of the samples.

The present values of $\mathrm{D}$ retention were several times lower than that measured by Manhard [6] for the same type of material exposed to a low-flux plasma at a similar temperature $(370 \mathrm{~K})$ to the highest fluence $\left(4.7 \times 10^{25} \mathrm{D} / \mathrm{m}^{2}\right)$. This confirms the fact that the $\mathrm{D}$ retention in $\mathrm{W}$ is flux-dependent. At the same time, the fluence dependence of $\mathrm{D}$ retention in the experiments of Manhard [6] also showed a slow D uptake in the samples at fluences above $10^{24} \mathrm{D} / \mathrm{m}^{2}$, which correlated with stagnation of blistering activity. A similar correlation was also observed after high-flux $\left(\sim 10^{24} \mathrm{D} / \mathrm{m}^{2} \mathrm{~s}\right)$ plasma exposures [17, 27]. Since in the present experiments the blistering pattern, D depth distributions, and total D retention barely changed with fluence, it is reasonable to assume that the lowest fluence used $\left(5 \times 10^{26} \mathrm{D} / \mathrm{m}^{2}\right)$ was already high enough that the concentration of defects produced by the high-flux plasma exposure almost saturated. In addition, as the D depth distributions indicate that more than 
$80 \%$ of D was retained within the subsurface region $(\leq 1.5 \mu \mathrm{m})$, it can be concluded that in the present experiments the $\mathrm{D}$ retention was dominated by trapping in the defects produced by the high-flux plasma exposure.

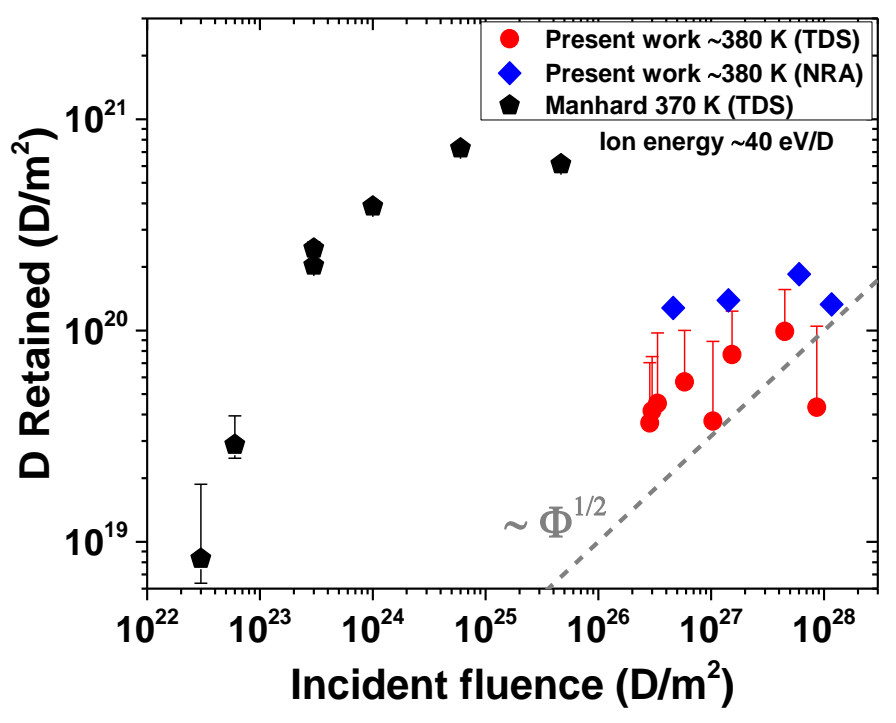

Fig. 5. Fluence dependence of $D$ retention in polycrystalline $W$ exposed to a $D$ plasma at a temperature of $\sim 380 \mathrm{~K}$ (in the sample centre). For the NRA measurements, the fluences in the sample centre are used, whereas for TDS measurements the fluences averaged over the whole exposed area of the sample are given. The data from Manhard [6] for the same type of material (hot-rolled W) exposed

to a low-flux D plasma $\left(10^{20} \mathrm{D} / \mathrm{m}^{2} \mathrm{~s}\right)$ with a mean ion energy of $38 \mathrm{eV} / \mathrm{D}$ at $370 \mathrm{~K}$ is shown for comparison.

The hypothesis about the influence of the damage induced by the plasma exposure on the D uptake can explain the discrepancy between the present experimental results and those reported by Doerner et al. [20], where the D retention in the samples almost obeyed the $\Phi^{1 / 2}$ dependence in the investigated fluence range (up to $2 \times 10^{28} \mathrm{D} / \mathrm{m}^{2}$ ). The experiments by Doerner et al. [20] were carried out at a sample temperature of $640 \mathrm{~K}$ and an incident flux of $1.6 \times 10^{23} \mathrm{D} / \mathrm{m}^{2} \mathrm{~s}$, where no apparent blisters or protrusions after the exposure were detected. Thus, the amount of the plasma-induced damage must have been much smaller compared to the present experiments, and, consequently, the D retention was dominated by intrinsic bulk defects in W.

Several additional factors could also contribute to the observed slow variation of the D retention in the samples with fluence. Firstly, the observed small cracks on the exposed surfaces can contribute to this, since D atoms diffusing from the implantation region can reach cracks and can recombine into $\mathrm{D}_{2}$ molecules on their surfaces, which results in an increase of the effective D reemission rate from the samples and, consequently, reduction of 
the effective D influx into the bulk of the samples. Secondly, fracture of the caps of blisters/protrusions can lead to release of $\mathrm{D}_{2}$ molecules trapped within their cavities and again provide additional surfaces for molecular recombination. Thirdly, enhanced D diffusion in the implantation region due to stresses in the lattice introduced by high solute concentrations can also lead to enhanced reemission. Fourthly, development of nanostructures on the surface also increases its effective surface area for recombination. Finally, at $\sim 380 \mathrm{~K}$ and such high fluxes the surface can be saturated with $\mathrm{D}$, thus, ion-induced desorption of adsorbed $\mathrm{D}$ from the surface can also take place.

\subsubsection{High temperatures}

In the samples exposed at $\sim 1140 \mathrm{~K}$ the $\mathrm{D}$ concentrations were below the sensitivity limit of $\operatorname{NRA}\left(\sim 10^{-5}\right.$ at. fr.).

In the case of the TDS measurements, the D release as $\mathrm{D}_{2}$ and HD molecules was below $10^{19} \mathrm{D} / \mathrm{m}^{2}$, but the $\mathrm{D}$ release as heavy water exceeded that of $\mathrm{D}_{2}$ and HD up to ten times, probably due to the partial oxidation of the surface (see discussion of Fig. 3 in Sect. 3.1.2). It should be kept in mind that in the case of exposure at $\sim 1140 \mathrm{~K}$ the difference between the temperature in the sample centre and edges was within $250 \mathrm{~K}$. Firstly, the 'cold' periphery of the sample has a higher surface area compared to the 'hot' centre. Secondly, due to the Arrhenius-like dependencies of detrapping rates from defects on temperature, colder regions exhibit a higher retention (in such temperature range [15]). Consequently, the measured total $\mathrm{D}$ retention gives an average number over a $250 \mathrm{~K}$ temperature gradient weighted by the corresponding surface areas, i.e. it cannot be definitely attributed to a certain exposure temperature. Due to the uncertainties in interpretation of $\mathrm{HDO}$ and $\mathrm{D}_{2} \mathrm{O}$ signals, the detailed numbers are not given here.

\section{Conclusions}

Hot-rolled polycrystalline $\mathrm{W}$ targets were exposed to a low-energy, high-flux D plasma at temperatures of $\sim 380 \mathrm{~K}$ and $\sim 1140 \mathrm{~K}$ up to very high fluences $\sim 10^{28} \mathrm{D} / \mathrm{m}^{2}$.

The exposure at $\sim 380 \mathrm{~K}$ resulted in severe surface modifications of the samples: appearance of a large number of dome-shaped blister-like structures (up to $10 \mu \mathrm{m}$ ) and stepped flat-topped protrusions (up to several $\mu \mathrm{m}$ ). In addition, stripe-like and sponge-like nano-scaled (up to $50 \mathrm{~nm}$ ) structures were formed. The cavities of blisters were solely formed 
due to inter-granular cracking, whereas the cavities of the protrusions were formed both due to inter- and intra-granular cracking. Despite more than one order of magnitude variation of the incident fluence, the number density and the average size of blisters and protrusions barely changed with increasing fluence. By comparing the present experimental results with the results obtained for the same type of material but at much lower incident ion fluxes, it is suggested that a high local solute D concentration, which can be established either via using high incident fluxes or low exposure temperatures, triggers the formation of small protrusions via intra-granular cracking.

The depth distributions of trapped D also demonstrated a rather small evolution with fluence after the exposure at $\sim 380 \mathrm{~K}$. Most of the D was trapped in a subsurface region located at depths smaller than $1.5 \mu \mathrm{m}$, which coincides with the depth up to which most of the cavities of blisters and protrusions were located. The total D inventory was moderate $\left(<2 \times 10^{20} \mathrm{D} / \mathrm{m}^{2}\right)$ and varied only slowly with fluence. The latter is attributed to small variations in the amount of near-surface defects produced by the high-flux plasma exposure (cavities of blisters and protrusions, and defects appearing during their creation) in the investigated fluence range. Furthermore, a network of small cracks was observed on the exposed surfaces, which can provide additional surface area for recombination of D atoms into molecules during the plasma exposure, thus, reducing the effective D influx into the bulk of $\mathrm{W}$, which then would lead to a reduction of the $\mathrm{D}$ accumulation rate at high fluences.

After the exposure at $\sim 1140 \mathrm{~K}$ no blisters, protrusions, and nanostructures were found on the exposed surfaces. However, wave-like and faceted terrace-like structures with the characteristic dimensions of several hundreds of nm were formed due to the plasma exposure. The concentrations of trapped D were very low $\left(<10^{-5}\right.$ at. fr).

Overall, the present experimental results indicate that the defects introduced during the plasma exposure determine the total $\mathrm{D}$ retention as well as its fluence dependence, and that the number and features of these defects strongly depend on the incident ion flux. Extrapolations to even higher fluences up to $10^{30} \mathrm{D} / \mathrm{m}^{2}$, which are expected for ITER, are difficult from current understanding. Thus, further experiments with even higher fluences than in the present study are necessary to assess the D retention at fluences relevant for ITER and next-step fusion devices. 


\section{Acknowledgements}

Helpful discussions with A. Manhard, L. Gao, and W. Jacob are gratefully acknowledged. The technical assistance of K. Bystrov, G. Matern, T. Dürbeck, J. Dorner, and M. Fußeder is gratefully acknowledged. This work was supported by the European Commission and carried out within the framework of the Erasmus Mundus International Doctoral College in Fusion Science and Engineering (FUSION-DC). The work was also partially supported by the funding received from the Euratom research and training programme 2014-2018 under grant agreement No 633053 (EUROfusion/Enabling Research programme). The views and opinions expressed herein do not necessarily reflect those of the European Commission.

DIFFER is a part of the Netherlands Organisation for Scientific Research (NWO) and a partner in the Trilateral Euregio Cluster TEC. 


\section{References}

[1] Y. Ueda, K. Schmid, M. Balden, J.W. Coenen, T. Loewenhoff, A. Ito, A. Hasegawa, C. Hardie, M. Porton, M. Gilbert, Status of the Development of Baseline High Heat Flux and Plasma Facing Materials for Fusion, submitted to Nuclear Fusion (2016).

[2] Y. Ueda, J.W. Coenen, G. De Temmerman, R.P. Doerner, J. Linke, V. Philipps, E. Tsitrone, Research status and issues of tungsten plasma facing materials for ITER and beyond, Fusion Engineering and Design, 89 (2014) 901-906.

[3] B. Lipschultz, J. Roth, J.W. Davis, R.P. Doerner, A.A. Haasz, A. Kalenbach, A. Kirschner, R.D. Kolasinski, A. Loarte, V. Philipps, K. Schmid, W.R. Wampler, G.M. Wright, D.G. Whyte, An assessment of the current data affecting tritium retention and its use to project towards $\mathrm{T}$ retention in ITER, Report PSFC/RR-10-4, Massachusetts Institute of Technology, Cambridge, Massachusetts, USA, 2010.

[4] T. Tanabe, Review of hydrogen retention in tungsten, Physica Scripta, T159 (2014) 014044 .

[5] A. Manhard, K. Schmid, M. Balden, W. Jacob, Influence of the microstructure on the deuterium retention in tungsten, Journal of Nuclear Materials, 415 (2011) S632-S635.

[6] A. Manhard, Deuterium inventory in tungsten after plasma exposure: a microstructural survey (PhD Thesis, Universität Augsburg), Report IPP 17/34, Max-Planck-Institut für Plasmaphysik, Garching, Germany, 2012.

[7] M. Balden, A. Manhard, S. Elgeti, Deuterium retention and morphological modifications of the surface in five grades of tungsten after deuterium plasma exposure, Journal of Nuclear Materials, 452 (2014) 248-256.

[8] Y. Zayachuk, I. Tanyeli, S. Van Boxel, K. Bystrov, T.W. Morgan, S.G. Roberts, Combined effects of crystallography, heat treatment and surface polishing on blistering in tungsten exposed to high-flux deuterium plasma, Nuclear Fusion, 56 (2016) 086007.

[9] A. Manhard, M. Balden, S. Elgeti, Quantitative Microstructure and Defect Density Analysis of Polycrystalline Tungsten Reference Samples after Different Heat Treatments, Practical Metallography, 52 (2015) 437-466.

[10] H. Eleveld, A. van Veen, Deuterium interaction with impurities in tungsten studied with TDS, Journal of Nuclear Materials, 191-194, Part A (1992) 433-438.

[11] A.D. Quastel, J.W. Davis, A.A. Haasz, R.G. Macaulay-Newcombe, Effect of post-D ${ }^{+}$ irradiation time delay and pre-TDS heating on D retention in single crystal tungsten, Journal of Nuclear Materials, 359 (2006) 8-16. 
[12] K.A. Moshkunov, K. Schmid, M. Mayer, V.A. Kurnaev, Y.M. Gasparyan, Air exposure and sample storage time influence on hydrogen release from tungsten, Journal of Nuclear Materials, 404 (2010) 174-177.

[13] M. Poon, R.G. Macaulay-Newcombe, J.W. Davis, A.A. Haasz, Flux dependence of deuterium retention in single crystal tungsten, Journal of Nuclear Materials, 307-311, Part 1 (2002) 723-728.

[14] M.H.J. 't Hoen, M. Balden, A. Manhard, M. Mayer, S. Elgeti, A.W. Kleyn, P.A. Zeijlmans van Emmichoven, Surface morphology and deuterium retention of tungsten after low- and high-flux deuterium plasma exposure, Nuclear Fusion, 54 (2014) 083014.

[15] L. Buzi, G. De Temmerman, B. Unterberg, M. Reinhart, T. Dittmar, D. Matveev, C. Linsmeier, U. Breuer, A. Kreter, G. Van Oost, Influence of tungsten microstructure and ion flux on deuterium plasma-induced surface modifications and deuterium retention, Journal of Nuclear Materials, 463 (2015) 320-324.

[16] V.K. Alimov, B. Tyburska-Püschel, S. Lindig, Y. Hatano, M. Balden, J. Roth, K. Isobe, M. Matsuyama, T. Yamanishi, Temperature dependence of surface morphology and deuterium retention in polycrystalline ITER-grade tungsten exposed to low-energy, high-flux D plasma, Journal of Nuclear Materials, 420 (2012) 519-524.

[17] Y. Zayachuk, M.H.J. 't Hoen, P.A. Zeijlmans van Emmichoven, D. Terentyev, I. Uytdenhouwen, G. van Oost, Surface modification of tungsten and tungsten-tantalum alloys exposed to high-flux deuterium plasma and its impact on deuterium retention, Nuclear Fusion, 53 (2013) 013013.

[18] Y.Z. Jia, G. De Temmerman, G.N. Luo, H.Y. Xu, C. Li, B.Q. Fu, W. Liu, Surface morphology and deuterium retention in tungsten exposed to high flux D plasma at high temperatures, Journal of Nuclear Materials, 457 (2015) 213-219.

[19] R.D. Kolasinski, M. Shimada, Y. Oya, D.A. Buchenauer, T. Chikada, D.F. Cowgill, D.C. Donovan, R.W. Friddle, K. Michibayashi, M. Sato, A multi-technique analysis of deuterium trapping and near-surface precipitate growth in plasma-exposed tungsten, Journal of Applied Physics, 118 (2015) 073301.

[20] R.P. Doerner, M.J. Baldwin, T.C. Lynch, J.H. Yu, Retention in tungsten resulting from extremely high fluence plasma exposure, Nuclear Materials and Energy 9 (2016) 89-92.

[21] L. Gao, U. von Toussaint, W. Jacob, M. Balden, A. Manhard, Suppression of hydrogeninduced blistering of tungsten by pre-irradiation at low temperature, Nuclear Fusion, 54 (2014) 122003. 
[22] G.J. van Rooij, V.P. Veremiyenko, W.J. Goedheer, B. de Groot, A.W. Kleyn, P.H.M. Smeets, T.W. Versloot, D.G. Whyte, R. Engeln, D.C. Schram, N.J.L. Cardozo, Extreme hydrogen plasma densities achieved in a linear plasma generator, Applied Physics Letters, 90 (2007) 121501.

[23] G. De Temmerman, J.J. Zielinski, S. van Diepen, L. Marot, M. Price, ELM simulation experiments on Pilot-PSI using simultaneous high flux plasma and transient heat/particle source, Nuclear Fusion, 51 (2011) 073008.

[24] A. Zahoor, W.J. Goedheer, Optimization and characterization of a Pilot-PSI cascaded arc with non-LTE numerical simulation of $\mathrm{Ar}, \mathrm{H}_{2}$ gases, Plasma Sources Science and Technology, 18 (2009) 015008.

[25] P.C. Stangeby, The Plasma Boundary of Magnetic Fusion Devices, IOP Publishing Ltd., Bristol and Philadelphia, 2000.

[26] H.Y. Xu, Y.B. Zhang, Y. Yuan, B.Q. Fu, A. Godfrey, G. De Temmerman, W. Liu, X. Huang, Observations of orientation dependence of surface morphology in tungsten implanted by low energy and high flux D plasma, Journal of Nuclear Materials, 443 (2013) 452-457.

[27] Y. Zayachuk, A. Manhard, M.H.J. 't Hoen, W. Jacob, P.A. Zeijlmans van Emmichoven, G. van Oost, Depth profiling of the modification induced by high-flux deuterium plasma in tungsten and tungsten-tantalum alloys, Nuclear Fusion, 54 (2014) 123013.

[28] Y.Z. Jia, W. Liu, B. Xu, G.N. Luo, C. Li, B.Q. Fu, G. De Temmerman, Nanostructures and pinholes on $\mathrm{W}$ surfaces exposed to high flux D plasma at high temperatures, Journal of Nuclear Materials, 463 (2015) 312-315.

[29] Y.Z. Jia, W. Liu, B. Xu, G.N. Luo, S.L. Qu, T.W. Morgan, G. De Temmerman, Mechanism for orientation dependence of blisters on $\mathrm{W}$ surface exposed to D plasma at low temperature, Journal of Nuclear Materials, 477 (2016) 165-171.

[30] H.Y. Xu, W. Liu, G.N. Luo, Y. Yuan, Y.Z. Jia, B.Q. Fu, G. De Temmerman, Blistering on tungsten surface exposed to high flux deuterium plasma, Journal of Nuclear Materials, 471 (2016) 51-58.

[31] M. Mayer, E. Gauthier, K. Sugiyama, U. von Toussaint, Quantitative depth profiling of deuterium up to very large depths, Nuclear Instruments and Methods in Physics Research Section B: Beam Interactions with Materials and Atoms, 267 (2009) 506-512.

[32] M. Mayer, SIMNRA User's Guide, Report IPP 9/113, Max-Planck-Institut für Plasmaphysik, Garching, Germany, 1997. 
[33] K. Schmid, U. von Toussaint, Statistically sound evaluation of trace element depth profiles by ion beam analysis, Nuclear Instruments and Methods in Physics Research Section B: Beam Interactions with Materials and Atoms, 281 (2012) 64-71.

[34] E. Salançon, T. Dürbeck, T. Schwarz-Selinger, F. Genoese, W. Jacob, Redeposition of amorphous hydrogenated carbon films during thermal decomposition, Journal of Nuclear Materials, 376 (2008) 160-168.

[35] P. Wang, W. Jacob, L. Gao, T. Dürbeck, T. Schwarz-Selinger, Comparing deuterium retention in tungsten films measured by temperature programmed desorption and nuclear reaction analysis, Nuclear Instruments and Methods in Physics Research Section B: Beam Interactions with Materials and Atoms, 300 (2013) 54-61.

[36] Relative Sensitivity Measurements of Gases, Gas Analysis Application Note 282, Hiden Analytical Ltd.

[37] S. Lindig, M. Balden, V.K. Alimov, T. Yamanishi, W.M. Shu, J. Roth, Subsurface morphology changes due to deuterium bombardment of tungsten, Physica Scripta, T138 (2009) 014040. 